\title{
BMJ Open Factors influencing subspecialty choice among medical students: a systematic review and meta-analysis
}

\author{
Yahan Yang, ${ }^{1,2}$ Jiawei $\mathrm{Li}^{3}{ }^{3}$ Xiaohang Wu, ${ }^{1}$ Jinghui Wang, ${ }^{1}$ Wangting $\mathrm{Li},{ }^{1} \mathrm{Yi} \mathrm{Zhu},{ }^{4,5}$ \\ Chuan Chen, ${ }^{4,6}$ Haotian Lin ${ }^{\oplus 7}$
}

To cite: Yang Y, Li J, Wu X, et al. Factors influencing subspecialty choice among medical students: a systematic review and meta-analysis. BMJ Open 2019;9:e022097. doi:10.1136/ bmjopen-2018-022097

- Prepublication history and additional material for this paper are available online. To view these files, please visit the journal online (http://dx.doi. org/10.1136/bmjopen-2018022097).

Received 3 February 2018 Revised 15 January 2019 Accepted 8 February 2019

Check for updates

(C) Author(s) (or their employer(s)) 2019. Re-use permitted under CC BY-NC. No commercial re-use. See rights and permissions. Published by BMJ.

For numbered affiliations see end of article.

Correspondence to

Dr Haotian Lin;

haot.lin@hotmail.com

\section{ABSTRACT}

Objective To characterise the contributing factors that affect medical students' subspecialty choice and to estimate the extent of influence of individual factors on the students' decision-making process.

Design Systematic review and meta-analysis.

Methods A systematic search of the Cochrane Library, ERIC, Web of Science, CNKI and PubMed databases was conducted for studies published between January 1977 and June 2018. Information concerning study characteristics, influential factors and the extent of their influence (EOI) was extracted independently by two trained investigators. EOI is the percentage level that describes how much each of the factors influenced students' choice of subspecialty. The recruited medical students include students in medical school, internship, residency training and fellowship, who are about to or have just made a specialty choice. The estimates were pooled using a random-effects meta-analysis model due to the between-study heterogeneity.

Results Data were extracted from 75 studies (882209 individuals). Overall, the factors influencing medical students' choice of subspecialty training mainly included academic interests $(75.29 \%)$, competencies $(55.15 \%)$, controllable lifestyles or flexible work schedules (53.00\%), patient service orientation (50.04\%), medical teachers or mentors (46.93\%), career opportunities (44.00\%), workload or working hours (37.99\%), income (34.70\%), length of training $(32.30 \%)$, prestige (31.17\%), advice from others (28.24\%) and student debt (15.33\%), with significant between-study heterogeneity $(p<0.0001)$. Subgroup analyses revealed that the EOI of academic interests was higher in developed countries than that in developing countries $(79.66 \%$ [ $95 \% \mathrm{Cl} 70.73 \%$ to $86.39 \%$ ] vs $60.41 \%$ [ $95 \% \mathrm{Cl} 43.44 \%$ to $75.19 \%$ ]; $Q=3.51$, $\mathrm{p}=0.02)$. The EOI value of prestige was lower in developed countries than that in developing countries $(23.96 \%[95 \% \mathrm{Cl}$ $19.20 \%$ to $29.47 \%$ ] vs $47.65 \%$ [ $95 \% \mathrm{Cl} 34.41 \%$ to $61.24 \%$ ]; $\mathrm{Q}=4.71, \mathrm{p}=0.01$ ).

Conclusions This systematic review and meta-analysis provided a quantitative evaluation of the top 12 influencing factors associated with medical students' choice of subspecialty. Our findings provide the basis for the development of specific, effective strategies to optimise the distribution of physicians among different departments by modifying these influencing factors.

\section{INTRODUCTION}

Because of the population ageing, increased workload on doctors through increased

\section{Strengths and limitations of this study}

- This is the first study that provides a systematic estimate of the factors associated with medical students' subspecialty choices.

- A large number of studies conducted in varied populations have been included.

- The differences in the characteristics of country, survey years, specialty, the type of data used and sample size across studies represent a major limitation of our study.

number of consultations and in managing patients with multimorbidity, the demand for physicians continues to increase; however, an imbalance in the supply of physicians in different subspecialties has become a growing concern in both developed and developing countries. ${ }^{1-5}$ Some specialties and subspecialties, such as family medicine and palliative medicine, ${ }^{67}$ are experiencing a desperate shortage of physicians, whereas other specialties and subspecialties, such as cardiology, ophthalmology and ear, nose and throat surgery, are highly competitive specialties with low success rate for candidates. ${ }^{89}$

Specialty choice is the product of a complex interconnection of student expectation, department expectation and competition for available spots, and student choice is where the choice begins. ${ }^{10}$ Previous studies have suggested that medical students' choice of subspecialty is essential to the maintenance of an adequate medical workforce and a balanced development of the medical system. ${ }^{11}{ }^{12}$ However, the influencing factors underlying students' subspecialty choice have not been systemically reviewed. Recent changes in the training and practice environment may influence medical students' career choice. ${ }^{13}$ Additionally, the variability in preferences over time and in students' attitudes towards career choices can further complicate this assessment. For example, a study in 
the UK indicated that half of the medical students made a definitive subspecialty choice during their first year of medical school. ${ }^{14}$ However, students were prone to changing their subspecialty preference during medical school and internship. ${ }^{15}$ Notably, students may also reject certain subspecialties during their medical school training, even those they have previously seriously considered. ${ }^{16}$ Therefore, identifying the factors that influence students' choice of subspecialty will enable a better understanding of the current shortage/overload of physicians in specific fields and contribute to policy-building and decision-making to improve the training and recruitment of students in the future.

We thus conducted a systematic review and a meta-analysis to investigate the influencing factors and the extent of their influence on the choice of subspecialty training among medical students. More specifically, we focused on the following questions. First, can we gain a better understanding of students' preferences for medical specialty according to the primary influencing factor? Second, do the subgroups according to world region and survey years examined in this study differ significantly with regard to the weight that students place on the identified influencing factor?

\section{METHODS}

We developed a review protocol (registration number: PROSPERO CRD42017053781) prior to commencing the study. The Preferred Reporting Items for Systematic Reviews and Meta-Analyses guidelines was used to ensure the reporting quality of this review (see online supplementary figure $\mathrm{S} 1) .{ }^{17}$

\section{Search strategy and study eligibility}

We performed a literature search in June 2018 using the Cochrane Library, Medline, Web of Science, CNKI and ERIC databases without language restrictions. Articles were screened by title, abstract and reference list, and by correspondence with study investigators. Potentially relevant papers were first identified by reviewing the titles and abstracts, and the full text of each retrieved article was then assessed. A detailed example of search strategy for Medline/PubMed is shown in online supplementary methods S1. Studies were included if they were systematic review or cross-sectional studies, reported data on medical students, were published in peer-reviewed journals and used a validated method to assess the extent of their influence (EOI) on the choice of subspecialty, such as paediatric gastroenterology and vascular surgery, or its corresponding specialty, such as paediatrics and surgery. Because of the differences between medical education systems in the world, the medical students we recruited include the students in medical school, internship, residency training and fellowship, students who are about to make a specialty choice and students who have just made a specialty choice. A guide to medical specialty, available at https://www.abms.org/member-boards/ specialty-subspecialty-certificates/, was used to identify the medical specialty and subspecialty of our research. We also conducted an additional search using OpenGrey. However, no additional articles were further included. All searches were performed using Google chrome (V.54.0.2840).

\section{Data extraction and quality assessment}

Each article was reviewed by two trained investigators (YY and JL) and the following information was independently extracted from each selected article using a standardised form: study design, geographic location, years of survey, journal, sample size, average age of the participants, the number and percentage of male participants and the influencing factors and the extent of their influence. A third investigator was consulted if disagreements occurred. Each study may involve one or several influencing factors. An 11-item checklist which was recommended by Agency for Healthcare Research and Quality (AHRQ), used for cross-sectional studies, ${ }^{18}$ available at https://www.ncbi. nlm.nih.gov/books/NBK35156/, was used to assess the quality of the studies. All discrepancies were resolved via discussion and consensus.

\section{Statistical analysis}

As considerable heterogeneity was expected because of the multiple sources of variances, a random effects meta-analysis model was used to estimate the influencing factors and the extent of their influence. ${ }^{19}$ Between-study heterogeneity was assessed using the Cochran's Q-test, and was quantified with the $\mathrm{I}^{2}$ statistic, which was calculated to describe the percentage of total variation caused by heterogeneity across studies, with $\geq 50 \%$ indicating considerable heterogeneity. ${ }^{20} 21$ Potential sources of heterogeneity were identified using meta-regression. ${ }^{22}$ Four categorical covariates were defined as potential sources of heterogeneity by examining the studies conducted in the USA versus the studies conducted in other countries, the studies conducted before 2010 versus those conducted after 2010, the studies concerning subspecialty only versus those that were not specific to a subspecialty, and the studies with a sample size $<200$ versus the studies with a sample size $\geq 200$. Subgroup analyses were performed for each factor in the studies in developed countries versus developing countries and studies conducted before 2010 versus after 2010. The EOI value of competencies in developing countries was not statistically significant $(81.21 \%$ [95\% CI $75.27 \%$ to $86.51 \%$ ], $\mathrm{p}=0.1436$ ), and no studies on the influence of student debt in developing countries were found. The Q-test based on the analysis of variance was used to compare the subgroups, with a significance threshold of $5 \%{ }^{23}$ The influence of individual studies on the overall EOI value was explored by serially excluding each study in a sensitivity analysis. Publication bias was investigated using a funnel plot test and Egger's test. ${ }^{24}$ Fill and trim approach, which imputes estimates from hypothetical negative unpublished reports, ${ }^{26}$ was also used to investigate the publication bias if the Egger's 
test was significant. All analyses were performed using R (V.3.3.1, The R Foundation, Vienna, Austria). The statistical tests were two-sided with a significance threshold of $\mathrm{p}<0.05$.

\section{Patient and public involvement}

Patients and the public were not involved in development of the research question and outcome measures, nor the study design. The study does not involve patient recruitment, and patients were not involved in conduct of the study. We plan to liaise closely with patients, special interest groups and charities in the dissemination of our results in printed and electronic media.

\section{RESULTS}

\section{Study characteristics}

Seventy-five cross-sectional studies involving a total of 882209 individuals that were published between January 1977 and May 2018 were included in the present research (table 1). Thirty-four studies were conducted in North America, twenty-four in Europe, seven in Asia, five in Oceania, three in Africa and two in South America. The median number of participants per study was 243 (range 37-29 227). Fourteen studies included students who had already selected subspecialties, whereas 61 did not. The influencing factors were ranked according to the frequency of occurrence and each factor was identified when at least five papers were available describing it. The influencing factors for subspecialty choice were then classified according to 17 aspects, including academic interests, controllable lifestyle or flexible work schedule (defined as flexibility that allows physicians to control the number of hours devoted to practising the specialty), competencies, patient service orientation, medical teachers or mentors, career opportunities, workload or working hours (characterised by the physician's time spent on professional responsibilities), income, prestige, length of training, advice from others (advice from family, friends and other students), student debt, experience with the subject, working environment, personality, gender and job security. Personality and gender are common factors that affect the choice of subspecialty among medical students, but most of the relevant literature has not reported on the extent of these factors' influence. Moreover, the funnel plots were clearly asymmetrical with regard to experience with the subject, the working environment and job variety, indicating the existence of publication bias. Thus, the analysis of the remaining 12 influencing factors were shown in this paper. Studies assessed for influencing factors using questionnaires validated to medical students asking the extent of certain factors the studies investigated. Quality assessment scores for the included studies are listed in table 1 . None of the studies received a point for the second AHRQ quality indicator, which requires studies to list the inclusion and exclusion criteria for exposed and unexposed subjects (cases and controls) or refer to previous publications, since no comparison studies were referenced in the analysed articles. For the remaining 10 criteria, 6 studies received nine points, 8 studies received eight points, 17 studies received seven points, 33 studies received six points, 9 studies received 5 points and 2 studies received four points (scores for individual studies are presented in online supplementary table S1).

\section{Primary analysis}

A meta-analysis was performed on the 12 influencing factors (table 2): academic interests (see online supplementary figure S2), competencies (see online supplementary figure S3), controllable lifestyle or flexible work schedule (see online supplementary figure S4), patient service orientation (see online supplementary figure S5), medical teachers or mentors (see online supplementary figure S6), career opportunities (see online supplementary figure S7), workload or working hours (see online supplementary figure S8), income (see online supplementary figure S9), length of training (see online supplementary figure S10), prestige (see online supplementary figure S11), advice from others (see online supplementary figure S12) and student debt (see online supplementary figure S13). All the factors were significant with evidence of between-study heterogeneity $(p<0.0001)$. A sensitivity analysis, in which the meta-analysis was serially repeated after the exclusion of each study, demonstrated that no individual study affected the overall extent of a factor's influence.

\section{Meta-regression and subgroup analysis}

We performed meta-regression to identify the potential sources of heterogeneity using common instructions when at least five studies were available and at least two studies were in each comparator subgroup (table 3). Some of the heterogeneities observed among the 12 factors can be partially explained by country, survey years, specialty and sample size.

EOI values were further analysed by subgroup (see online supplementary table S2) according to world region (figure 1) and survey year (figure 2). The EOI value of academic interests in developed countries was higher than that in developing countries $(79.66 \%$ [95\% CI $70.73 \%$ to $86.39 \%$ vs $60.41 \%$ [95\% CI $43.44 \%$ to 75.19\%]; $\mathrm{Q}=3.51, \mathrm{p}=0.02)$. Conversely, a lower EOI value of prestige was found in studies conducted in developed countries than in developing countries $(23.96 \%$ [95\% CI $19.20 \%$ to $29.47 \%$ ] vs $47.65 \%$ [ $95 \%$ CI $34.41 \%$ to 61.24\%]; $\mathrm{Q}=4.71, \mathrm{p}=0.01$ ). No statistically significant subgroup differences in the EOI values of the other influencing factors were noted between developed countries and developing countries. In addition, no statistically significant differences in the EOI values of the influencing factors were observed when subgroup analysis was performed by survey year.

\section{Assessment of publication bias}

We generated a funnel plot with proportion as the abscissa and SE as the ordinate. A visual inspection of the funnel 
Table 1 Selected characteristics of the 75 studies included in this systematic review and meta-analysis

\begin{tabular}{|c|c|c|c|c|c|c|}
\hline First author, year & Country & Survey years & Sample size & Average age & Men, No. (\%) & Scores \\
\hline Smith et al, ${ }^{43} 2015$ & UK & 2012 & 2978 & NR & NR & 6 \\
\hline Cochran et al, ${ }^{44} 2005$ & USA & 2002 & 408 & 27.2 & $214(52.45)$ & 5 \\
\hline Hauer et al, ${ }^{45} 2008$ & USA & 2007 & 1177 & NR & NR & 6 \\
\hline Johnson et al, ${ }^{46} 2012$ & USA & 2012 & 622 & NR & NR & 6 \\
\hline Kiolbassa et al, ${ }^{47} 2011$ & Germany & 2010 & 1114 & 24.1 & 408 (36.62) & 5 \\
\hline Klingensmith et al, ${ }^{48} 2015$ & USA & 2013 & 792 & NR & $539(68.06)$ & 6 \\
\hline Lee et al, ${ }^{49} 2012$ & USA & 2012 & 100 & NR & $58(58)$ & 7 \\
\hline Macdonald et al, ${ }^{50} 2012$ & New Zealand & 2011 & 134 & NR & $79(58.96)$ & 7 \\
\hline Parsa et $a l,,^{39} 2010$ & Iran & 2006-2007 & 137 & 27.34 & $49(35.77)$ & 7 \\
\hline Paiva et al, ${ }^{51} 1982$ & USA & 1982 & 144 & NR & NR & 6 \\
\hline Ni Chroinin et al, ${ }^{52} 2013$ & UK & 2009-2011 & 274 & NR & $112(40.89)$ & 7 \\
\hline Newton et al, ${ }^{34} 2005$ & USA & 1998-2004 & 1258 & NR & $642(51.03)$ & 8 \\
\hline Rogers et al, ${ }^{53} 1990$ & USA & 1989 & 266 & NR & 205 (77.07) & 6 \\
\hline Abendroth et al, ${ }^{54} 2014$ & Germany & 2007-2012 & 45 & NR & $14(31)$ & 7 \\
\hline Alawad et al, ${ }^{55} 2015$ & USA & 2010-2011 & 45 & NR & $36(80)$ & 8 \\
\hline Azizzadeh et al, ${ }^{56} 2003$ & USA & 2002 & 130 & NR & NR & 6 \\
\hline Celenza et $a l,{ }^{57} 2012$ & Australia & 2009 & 216 & NR & $121(56.02)$ & 8 \\
\hline Dolan-Evans et al, ${ }^{58} 2014$ & Australia & 2013 & 419 & NR & $215(51.31)$ & 8 \\
\hline Boyd et al, 2009 & USA & 2005-2006 & 5848 & NR & $2982(50.99)$ & 8 \\
\hline Egerton et al, ${ }^{60} 1985$ & Ireland & 1977-1981 & 134 & 30 & $82(61.19)$ & 6 \\
\hline Diderichsen et al, ${ }^{61} 2013$ & Sweden & 2006-2009 & 372 & 27 & $157(42.20)$ & 6 \\
\hline Ferrari et al, ${ }^{62} 2013$ & Italy, UK & 2009-2011 & 45 & 25 & NR & 9 \\
\hline Freire et $a l,{ }^{63} 2011$ & Brazil & 2006-2008 & 290 & 23 & $102(35.17)$ & 7 \\
\hline Buddeberg-Fischer et al, ${ }^{64} 2006$ & Switzerland & $2001-2003$ & 522 & 31.1 & $241(46.17)$ & 9 \\
\hline Dorsey et al, ${ }^{65} 2005$ & USA & 2003 & 11029 & NR & $4964(45.01)$ & 6 \\
\hline Ekenze et al, ${ }^{66} 2013$ & Nigeria & 2009-2010 & 96 & 25.9 & NR & 7 \\
\hline Barikani et al, ${ }^{67} 2012$ & Australia & 2008-2009 & 49 & 21.7 & NR & 6 \\
\hline Bittaye et al, ${ }^{68} 2012$ & Gambia & 2011 & 106 & 24.1 & $48(45.28)$ & 6 \\
\hline Bonura et al, ${ }^{69} 2016$ & USA & 2015 & 590 & NR & $321(54.40)$ & 9 \\
\hline Al-Fouzan et al, ${ }^{70} 2012$ & Kuwait & 2011-2012 & 144 & NR & NR & 7 \\
\hline AlKot et al, ${ }^{71} 2015$ & Egypt & 2013 & 451 & 21.8 & NR & 7 \\
\hline Borges et al, ${ }^{72} 2009$ & USA & 2001-2005 & 341 & NR & NR & 5 \\
\hline Budd et al, ${ }^{73} 2011$ & UK & 2011 & 870 & 22 & NR & 7 \\
\hline Corrigan et al, ${ }^{74} 2007$ & Ireland & 2007 & 222 & NR & $142(63.96)$ & 7 \\
\hline Davis et al, ${ }^{75} 2016$ & UK & 2016 & 173 & NR & $76(43.93)$ & 7 \\
\hline Deutsch et al, ${ }^{76} 2015$ & Germany & 2011 & 659 & 27.9 & NR & 8 \\
\hline Gardner et al, ${ }^{77} 2014$ & Australia & 1993-2005 & 631 & NR & NR & 7 \\
\hline Dias et al, ${ }^{78} 2013$ & UK & 2013 & 495 & NR & 438 (88.48) & 5 \\
\hline Goltz et al, ${ }^{79} 2013$ & USA & 2012 & 102 & 24.5 & $34(33.33)$ & 6 \\
\hline Gupta et $a l,{ }^{80} 2013$ & India & 2013 & 243 & NR & $179(73.36)$ & 6 \\
\hline Hanzlick et al, ${ }^{81} 2008$ & USA & 2006 & 161 & NR & NR & 6 \\
\hline Harris et al,, 2005 & USA & 1991-2002 & 104 & NR & $53(50.96)$ & 6 \\
\hline Hauer et al, ${ }^{83} 2008$ & USA & 2008 & 80 & NR & NR & 6 \\
\hline Labiris et al, ${ }^{84} 2014$ & Greece & 2014 & 111 & 23.6 & $55(49.54)$ & 6 \\
\hline Lambert et al, ${ }^{85} 2008$ & UK & 2007 & 17393 & NR & NR & 6 \\
\hline Shah et al, ${ }^{86} 2012$ & USA & 2011 & 892 & NR & NR & 6 \\
\hline
\end{tabular}




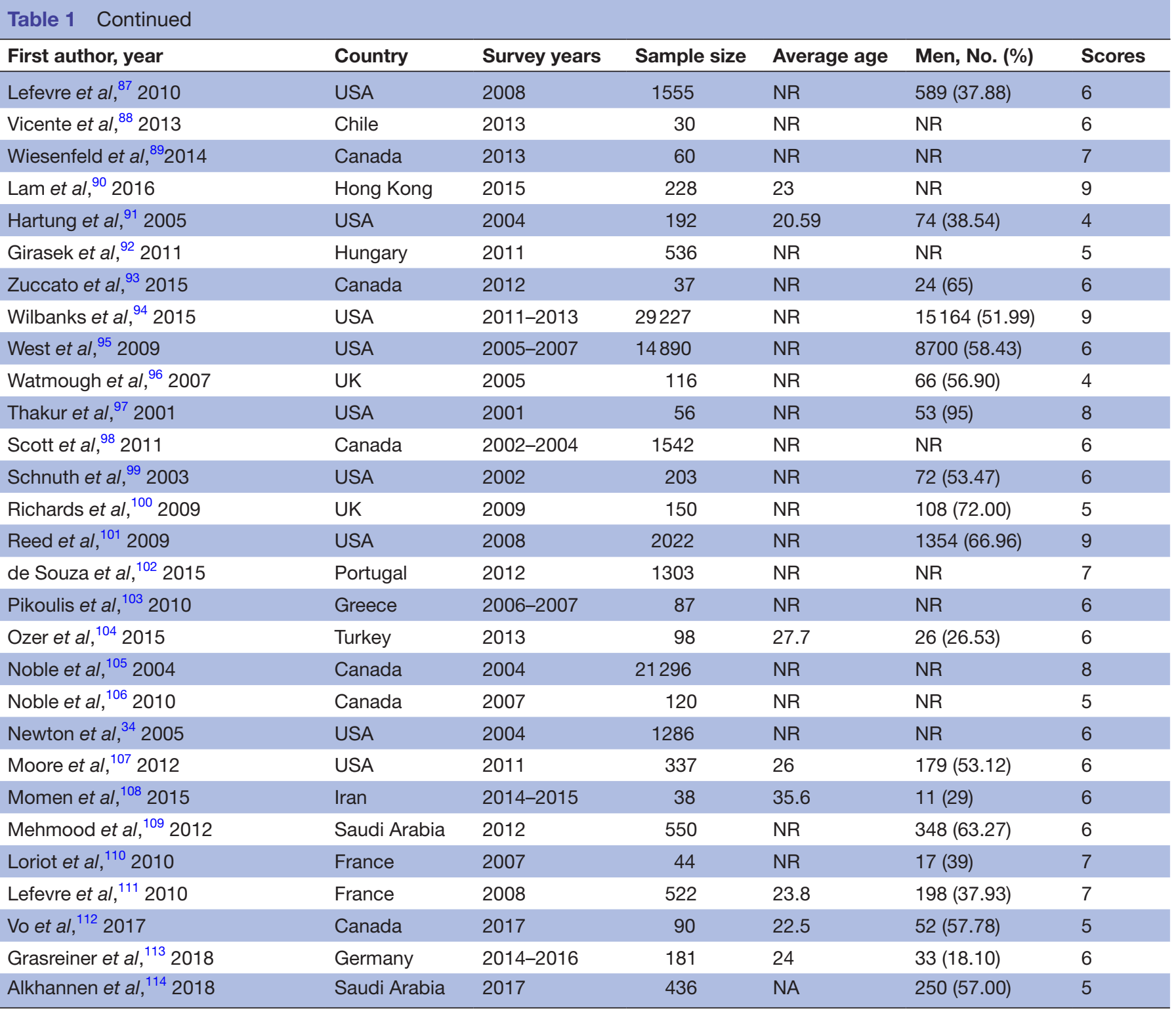

Footnotes, scores: quality score of the AHRQ scale.

plots revealed minimal asymmetry among the various influencing factors (see online supplementary figure S14), and the results were concentrated in the narrow upper part of the graph. There was evidence of small study effect in the meta-analysis of 'patient service orientation' (Egger's test, $\mathrm{p}=0.02$ ). However, the trim-and-fill method showed the publication bias-corrected estimate remained statistically significant $(63.79 \%, 95 \%$ CI $58.20 \%$ to $69.04 \%$ ).

\section{DISCUSSION}

\section{Implications}

This systematic review and meta-analysis involved 75 studies with 882209 medical students. Twelve influencing factors were analysed. These factors can be classified into two categories: economic factors and non-economic factors. We found that the EOI of the economic factors, including income $(34.70 \%)$ and student debt $(15.33 \%)$, may not depend on the region's level of economic development. However, income remained a major influencing factor in the process of choosing a specialty or subspecialty. In the USA, $15 \%$ of full-time family medicine physicians earned less than $\$ 100000$ in 2004 , which is significantly less than the income earned by invasive cardiologists (median income $=\$ 427815$ ), neurosurgeons (median income $=\$ 211094$ ) and orthopaedists (median income $=\$ 335646) .{ }^{27}$ This economic inequality made family medicine less attractive to medical school graduates. ${ }^{28}$ Benefits such as health insurance and tuition reimbursement have been shown to be the most common economic incentives used to attract applicants. ${ }^{29}$

The non-economic factors can be divided into individual factors, specialty-related factors and others. First, individual factors, including academic interest and 
Table 2 Meta-analyses of the factors influencing medical students' choice of subspecialty

\begin{tabular}{|c|c|c|c|c|c|c|c|c|c|}
\hline \multirow[b]{2}{*}{ Factor } & \multirow{2}{*}{$\begin{array}{l}\text { No. of } \\
\text { studies }\end{array}$} & \multirow{2}{*}{$\begin{array}{l}\text { Total no. of } \\
\text { participants }\end{array}$} & \multirow{2}{*}{$\begin{array}{l}\text { EOI } \\
\text { value } \\
(\%)\end{array}$} & \multicolumn{2}{|c|}{$\begin{array}{l}95 \mathrm{Cl} \% \text { of extent } \\
\text { of influence } \\
\text { value }\end{array}$} & \multirow{2}{*}{$\begin{array}{l}\text { Cochran's } \\
\mathbf{Q}\end{array}$} & \multirow[b]{2}{*}{$I^{2}(\%)$} & \multirow[b]{2}{*}{$\tau^{2}$} & \multirow[b]{2}{*}{$P$ value } \\
\hline & & & & Lower & Upper & & & & \\
\hline Academic interests & 38 & 82366 & 75.29 & 66.93 & 82.11 & 14719.76 & 99.70 & 1.60 & $<0.0001$ \\
\hline Competencies & 17 & 76515 & 55.15 & 33.63 & 74.90 & 23572.74 & 99.90 & 3.44 & $<0.0001$ \\
\hline $\begin{array}{l}\text { Controllable lifestyle or flexible } \\
\text { work schedule }\end{array}$ & 44 & 101001 & 53.00 & 47.90 & 58.03 & 8624.46 & 99.50 & 0.45 & $<0.0001$ \\
\hline Patient service orientation & 37 & 46572 & 50.04 & 44.65 & 55.43 & 2668.79 & 98.70 & 0.41 & $<0.0001$ \\
\hline Medical teachers or mentors & 32 & 85071 & 46.93 & 37.77 & 56.30 & 15216.32 & 99.80 & 1.14 & $<0.0001$ \\
\hline Career opportunities & 38 & 81923 & 44.00 & 32.26 & 48.78 & 13553.20 & 99.70 & 1.15 & $<0.0001$ \\
\hline Workload or working hours & 20 & 22051 & 37.99 & 29.59 & 47.19 & 584.81 & 98.30 & 0.69 & $<0.0001$ \\
\hline Income & 50 & 109791 & 34.70 & 28.36 & 41.62 & 16952.48 & 99.70 & 1.09 & $<0.0001$ \\
\hline Length of training & 18 & 42046 & 32.30 & 27.61 & 37.37 & 917.21 & 98.10 & 0.20 & $<0.0001$ \\
\hline Prestige & 26 & 30629 & 31.17 & 26.32 & 37.69 & 1464.67 & 98.30 & 0.52 & $<0.0001$ \\
\hline Advice from others & 18 & 82692 & 28.24 & 22.26 & 34.23 & 7679.73 & 99.80 & 0.02 & $<0.0001$ \\
\hline Student debt & 8 & 38917 & 15.33 & 10.96 & 21.03 & 574.81 & 98.80 & 0.27 & $<0.0001$ \\
\hline
\end{tabular}

competencies, have a considerable impact on students' subspecialty choice, with EOI values of $75.29 \%$ and $55.15 \%$, respectively. In addition, in the subgroup analysis, although academic interests were less influential in developing countries than in developed countries (79.66\% [95\% CI $70.73 \%$ to $86.39 \%$ vs $60.41 \%$ [95\% CI $43.44 \%$ to $75.19 \%$ ]; $\mathrm{Q}=3.51, \mathrm{p}=0.02$ ), they were still the most influential of the 12 factors regardless of regional economic level. These findings indicate that subspecialties with a shortage of manpower may attract more students by increasing students' interests and improving the quality of education. Previous studies indicated that early specialty exposure in medical education may arouse students' academic interest and improve their clinical competence. ${ }^{28}{ }^{30}$ For example, an elective extracurricular programme designed to facilitate early contact with family medicine physicians was found to significantly improve students' interest and clinical skills, especially communication skills, in family medicine. ${ }^{31}$ Furthermore, dispelling myths and espousing the positive aspects of a discipline may provide a better understanding of certain specialties; this approach could also be effective in increasing students' academic interest. ${ }^{32}$ For instance, family medicine is often considered a discipline that requires less professional skills and knowledge. This misconception demotivates students from choosing family medicine as their future career specialty, and this trend may eventually lead to a shortage of family physicians.$^{32}$ Eliminating such prejudices may help students pay greater attention to the areas in short supply and restore their interests in other specialties.

Second, the specialty-related factors included controllable lifestyle/flexible work schedule (EOI of $53.00 \%$ ), career opportunities (EOI of $44.00 \%$ ), workload (EOI of $37.99 \%$ ) and training length (EOI of $32.30 \%$ ). Of these factors, lifestyle varied between different areas. Additionally, although certain specialties, such as general surgery, seem to have an adequate number of surgeons on a per capita basis in the USA, there is still a poor geographic distribution within the surgical workforce according to the type of surgical practice. ${ }^{33}$ The inflexible lifestyle is a common reason that students perceive surgery to be less attractive. ${ }^{33}$ Reorganisation of expected work hours within shared practices and the increased use of physician extenders and technologies such as electronic medical records may give physicians more flexibility in work schedules. ${ }^{34}$ Moreover, providing promotion opportunities and shortening the length of training are possible strategies to recruit new staff in subspecialties that require a long period of postgraduate residency training, such as neurosurgery. ${ }^{35}$

Finally, other factors such as service orientation (EOI of $50.74 \%$ ), medical teachers or mentors (EOI of $46.93 \%$ ), prestige (EOI of $34.68 \%$ ) and advice from others (EOI of $28.24 \%$ ) also contribute to the decision-making process of medical students. For example, the desire to care for patients with end-stage diseases contributed to the decision to enter palliative medicine in $86 \%$ of the medical students. ${ }^{7}$ Additionally, exposure to mentors in a particular clinical field such as internal medicine has been strongly associated with medical students' choice of clinical field. ${ }^{36}$ Moreover, improving the occupational prestige of areas such as family medicine, pathology and radiology may help reshape the distribution of the workforce. . $^{303738}$

In our study, several findings are especially noteworthy. First, interest was far more important than income in deciding subspecialty. In our study, interest was the top-ranked influencing factor (EOI of 75.29\%) of subspecialty choice, while income was ranked lower (EOI of 
Table 3 Meta-regression of the extent of influence value stratified by study-level characteristics

\begin{tabular}{|c|c|c|c|c|}
\hline \multirow[b]{2}{*}{ Factor } & \multirow[b]{2}{*}{ Estimate } & \multicolumn{2}{|c|}{$95 \mathrm{Cl} \%$ of estimate } & \multirow[b]{2}{*}{$P$ value } \\
\hline & & Lower & Upper & \\
\hline \multicolumn{5}{|c|}{ Academic interests } \\
\hline Country & -0.2314 & -1.1575 & 0.6946 & 0.6302 \\
\hline Survey years & 0.3811 & -0.3580 & 1.1202 & 0.2711 \\
\hline Specialty & -0.4892 & -1.5345 & 0.5562 & 0.4008 \\
\hline Sample size & 0.2362 & -0.5488 & 1.0212 & 0.6537 \\
\hline \multicolumn{5}{|l|}{ Competencies } \\
\hline Country & 0.6946 & -1.1461 & 0.8938 & 0.8376 \\
\hline Survey years & -1.0418 & -2.0950 & 0.0114 & 0.0151 \\
\hline Specialty & 0.0904 & -1.5786 & 1.7594 & 0.9398 \\
\hline Sample size & -0.5720 & -1.8606 & 0.7166 & 0.5823 \\
\hline \multicolumn{5}{|c|}{ Controllable lifestyle or flexible work schedule } \\
\hline Country & -0.1261 & -1.1461 & 0.8938 & 0.9614 \\
\hline Survey years & -0.0001 & -0.4052 & 0.4051 & 0.9822 \\
\hline Specialty & -0.8989 & -1.4979 & -0.3000 & 0.0035 \\
\hline Sample size & -0.0518 & -0.4396 & 0.3361 & 0.7203 \\
\hline \multicolumn{5}{|c|}{ Patient service orientation } \\
\hline Country & -0.6238 & -1.3118 & 0.0642 & 0.0833 \\
\hline Survey years & -0.0414 & -0.6912 & 0.6083 & 0.8524 \\
\hline Specialty & -1.5982 & -2.5227 & -0.6737 & 0.0010 \\
\hline Sample size & -0.1157 & -0.7473 & 0.5159 & 0.6358 \\
\hline \multicolumn{5}{|c|}{ Medical teachers or mentors } \\
\hline Country & 0.7395 & 0.3117 & 1.1674 & 0.0007 \\
\hline Survey years & 0.1133 & -0.3580 & 0.5845 & 0.6376 \\
\hline Specialty & 0.0605 & -0.4441 & 0.5652 & 0.8141 \\
\hline Sample size & -0.1202 & -0.5567 & 0.3163 & 0.5894 \\
\hline \multicolumn{5}{|c|}{ Career opportunities } \\
\hline Country & 0.1075 & -0.7030 & 0.9179 & 0.5828 \\
\hline Survey years & 0.3284 & -0.3913 & 1.0480 & 0.7546 \\
\hline Specialty & -0.9292 & -1.8015 & -0.0570 & 0.0077 \\
\hline Sample size & 0.3654 & 0.1156 & 1.5478 & 0.0081 \\
\hline \multicolumn{5}{|c|}{ Workload or working hours } \\
\hline Country & -0.4535 & -1.5086 & 0.6016 & 0.3981 \\
\hline Survey years & 0.4624 & -0.5417 & 1.4665 & 0.3922 \\
\hline Specialty & -0.9878 & -2.1727 & 0.1972 & 0.1070 \\
\hline Sample size & 0.0982 & -0.8589 & 1.0553 & 0.8205 \\
\hline \multicolumn{5}{|l|}{ Income } \\
\hline Country & 0.1058 & -0.4665 & 0.6781 & 0.7390 \\
\hline Survey years & 0.0999 & -0.4379 & 0.6377 & 0.8774 \\
\hline Specialty & -0.6457 & -1.3267 & 0.0352 & 0.0480 \\
\hline Sample size & 0.0523 & -0.4826 & 0.5872 & 0.6786 \\
\hline \multicolumn{5}{|c|}{ Length of training } \\
\hline Country & -0.1559 & -1.2782 & 0.9664 & 0.7854 \\
\hline Survey years & -0.2158 & -1.4089 & 0.9772 & 0.7229 \\
\hline Specialty & 0.3959 & -0.9585 & 1.7502 & 0.5667 \\
\hline
\end{tabular}




\begin{tabular}{lcccc}
\hline Table 3 Continued & & & \\
& & & \\
Factor & Estimate & Lower & Upper & P value \\
\cline { 4 - 5 } Sample size & 0.1565 & -0.6631 & 0.9761 & 0.7082 \\
Prestige & & & & \\
Country & -0.3346 & -1.0799 & 0.4106 & 0.3485 \\
$\quad$ Survey years & -0.4513 & -1.1378 & 0.2352 & 0.0950 \\
$\quad$ Specialty & -1.0112 & -1.8980 & -0.1244 & 0.0172 \\
$\quad$ Sample size & 0.0355 & -0.6013 & 0.6723 & 0.5214 \\
Advice from others & & & & \\
Country & -0.0097 & -0.0722 & 0.0529 & 0.9328 \\
$\quad$ Survey years & -0.0861 & -0.1471 & -0.0251 & 0.0057 \\
$\quad$ Specialty & -0.2017 & -0.2790 & -0.1244 & $<0.0001$ \\
$\quad$ Sample size & 0.2125 & 0.1309 & 0.2941 & $<0.0001$ \\
Student debt & & & & \\
Country & 2.7853 & 2.0544 & 3.5162 & 0.0001 \\
$\quad$ Survey years & -0.1567 & -0.6707 & 0.3573 & 0.5502 \\
$\quad$ Sample size & -0.5248 & -1.0108 & -0.0388 & 0.0343 \\
\hline
\end{tabular}

$34.70 \%)$. This finding argues against the possible default belief that raising physician's wages alone could solve the uneven distribution of clinicians among subspecialties. Our findings highlight that cultivating and stimulating students' professional interests may help improve the maldistribution of medical resources in a more efficient and cost-saving manner.

Second, improving abilities in a certain subspecialty of interest can greatly affect medical students' professional choice. In our study, competencies ranked second in influence, which may reflect the impact of admission conditions on students' choice of subspecialty. Hence, to reduce the risk that students are restricted to the subspecialty of their interest due to a lack of personal skills, medical education should focus more on enhancing students' personal competencies in addition to their academic interests.

Third, balancing medical resources is a complex process in practical terms, as the influencing factors are not mutually exclusive. The shortage of physicians in certain subspecialties may increase physician workload, resulting in less time for teaching. Hence, the quality of teaching cannot be guaranteed, and students may tend to avoid choosing these subspecialties, thus worsening the imbalance in the medical workforce. Additionally, some of the 12 factors identified are not amenable to practical interventions. For example, prestige cannot be immediately increased using interventional strategies. ${ }^{37}$ Overall,

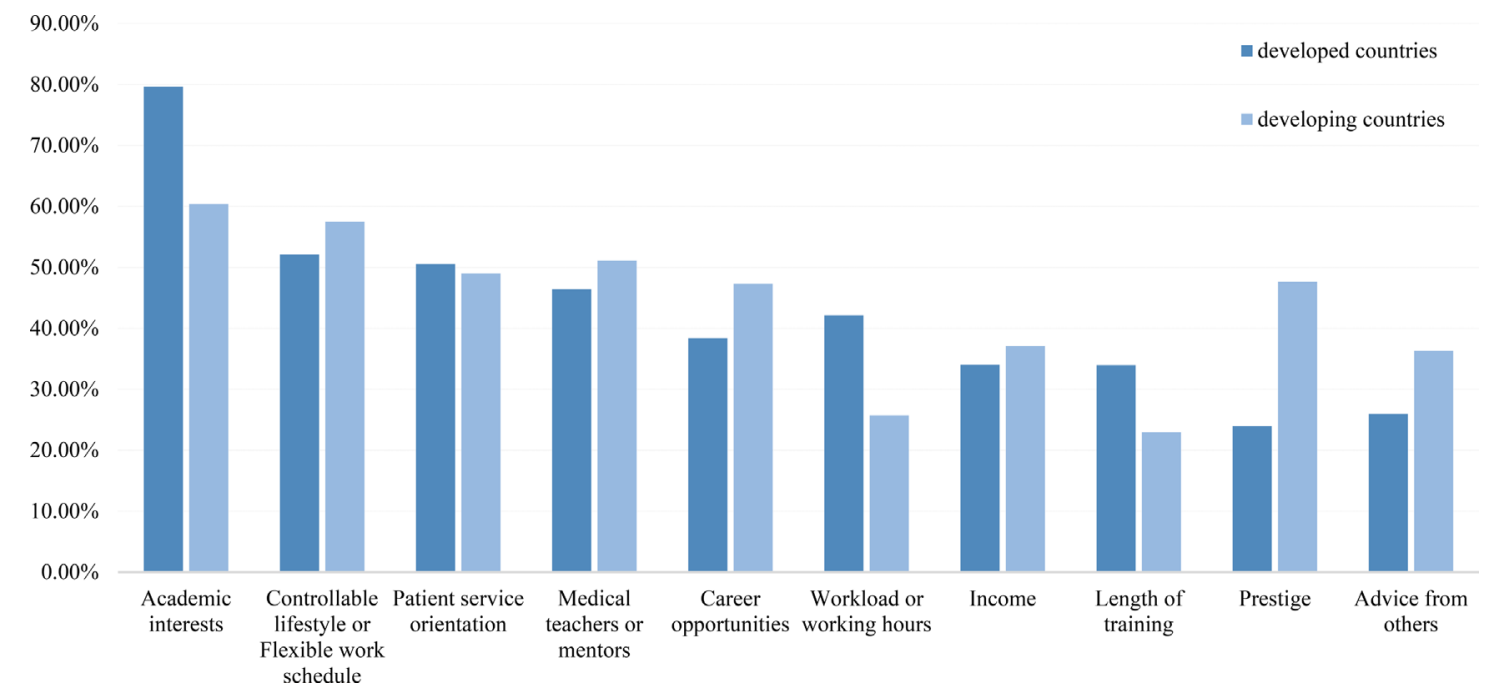

Figure 1 Bar graph of the meta-analyses of the factors influencing medical students' choice of subspecialty stratified by region. 


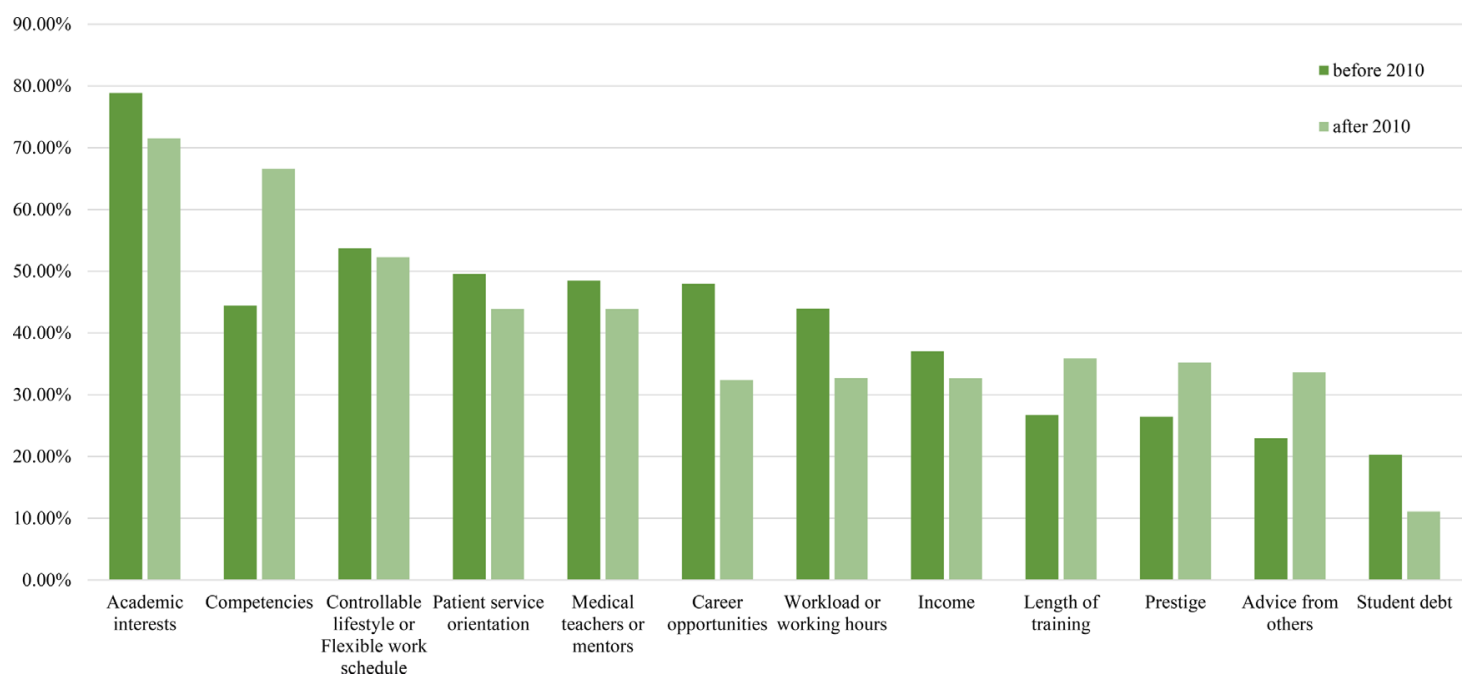

Figure 2 Bar graph of the meta-analyses of the factors influencing medical students' choice of subspecialty stratified by survey year.

effective strategies must be multipronged and incorporate several different aspects, and maldistribution in the workforce should not be tackled through a simple adjustment of one influencing factor.

\section{Interpretations of the results of this meta-analysis}

Our meta-regression stratified by the study-level characteristics found that country, survey years, subspecialty and sample size may contribute to the heterogeneity between studies. There was no significant difference in the sensitivity analysis, which indicated that the results of the meta-analysis were convincing. The funnel plots and Egger's tests revealed that most of the publication bias was small ( $p>0.05)$, except for the meta-analysis of 'patient service orientation'. Moreover, the majority of the studies collected in the database were from developed countries rather than developing countries.

\section{Limitations}

Several limitations should be considered when interpreting the findings of this study. First, the students involved in our study included medical students at different stages of their medical education. Students' perception about different subspecialties may change during medical training until the students applies for specialty training. For example, compared with an intern, a freshman student may place greater emphasis on income and prestige when considering a career choice. ${ }^{39}$ A subgroup analysis stratified by the stages of medical education and a secondary meta-analysis of longitudinal studies may better reflect changes in influencing factors and the extent of their influence over time. Second, our meta-analysis summarised the data from different geographic regions around the world, and the general conclusions may not be appropriate to guide policy development in each region. Enhanced effort is needed to develop specific intervention strategies according to the specific economic level, religious beliefs, healthcare system, educational system and endemic diseases of different countries and regions. Subgroup analysis stratified by organisational and medical training factors would provide more information of the factors influencing subspecialty choice among medical students. Third, the surveys in the various studies were also conducted using different methods. Most of the questionnaires used a Likert scale. Therefore, when we converted the results to a percentage representing the extent of a factor's influence, the Likert scale items were treated as interval data. ${ }^{40-42}$ Consequently, there may have been differences in the conversion process. Finally, the analysis relied on aggregated published data. A multicentre prospective study would provide more accurate estimate of the influencing factors and the extent of their influence on medical students' choice of subspecialty.

\section{CONCLUSION}

In conclusion, this systematic review and meta-analysis provided a summary evaluation of 12 influencing factors and the extent of their influence on the choice of subspecialty training among medical students. Understanding students' attitudes toward their subspecialty decision-making process could provide the basis for developing strategies to increase the attractiveness of subspecialties experiencing a shortage of manpower, thereby balancing the distribution of medical recourses.

\section{Author affiliations}

${ }^{1}$ State Key Laboratory of Ophthalmology, Sun Yat-Sen University Zhongshan Ophthalmic Center, Guangzhou, China

${ }^{2} Z$ hongshan School of Medicine, Sun Yat-Sen University, Guangzhou, China ${ }^{3}$ Zhongshan School of Mathematics, Sun Yat-Sen University, Guangzhou, China ${ }^{4}$ Department of Molecular and Cellular Pharmacology, University of Miami School of Medicine, Miami, Florida, USA

${ }^{5}$ Cataract, Sun Yat-Sen University Zhongshan Ophthalmic Center, Guangzhou, China ${ }^{6}$ State Key Laboratory of Ophthalmology, Zhongshan Ophthalmic Center, Sun Yatsen University, Guangzhou, China

${ }^{7}$ Cataract, State Key Laboratory of Ophthalmology, Zhongshan Ophthalmic Center, Sun Yat-sen University, Guangzhou, China 
Contributors HL contributed to the conceptualising and design of the study and to research funding, coordinated the research and oversaw the project. YY, JL and XW contributed to data collection and interpretation, and to data analysis. JW, YZ, CC and WL contributed to the design of the study. All authors contributed to the drafting and revision of the paper and approved the final manuscript for publication.

Funding The principal investigator of this study (Haotian Lin) is currently supported by National key R \& D project (2018YFC010302), the Key Research Plan for the National Natural Science Foundation of China Cultivation Project (91546101), the National Natural Science Foundation of China (81770967), the Fundamental Research Funds for the Central Universities (16ykjc28), the Guangdong Provincial Natural Science Foundation for Distinguished Young Scholars of China (2014A030306030), the Guangdong Province Universities and Colleges Youth Pearl River Scholar Funded Scheme (2016), the Clinical Research and Translational Medical Center of Pediatric Cataract in Guangzhou City (201505032017516) and Ministry of Science and Technology of China Grants (2015CB964600).

Disclaimer These sponsors and funding organisations had no role in the design or performance of this study.

Competing interests None declared.

Patient consent for publication Not required.

Provenance and peer review Not commissioned; externally peer reviewed.

Data sharing statement Extracted data are available upon request to the corresponding author.

Open access This is an open access article distributed in accordance with the Creative Commons Attribution Non Commercial (CC BY-NC 4.0) license, which permits others to distribute, remix, adapt, build upon this work non-commercially, and license their derivative works on different terms, provided the original work is properly cited, appropriate credit is given, any changes made indicated, and the use is non-commercial. See: http://creativecommons.org/licenses/by-nc/4.0/.

\section{REFERENCES}

1. Zurn P, Dal Poz MR, Stilwell B, et al. Imbalance in the health workforce. Hum Resour Health 2004;2:13.

2. Diallo K, Zurn P, Gupta N, et al. Monitoring and evaluation of human resources for health: an international perspective. Hum Resour Health 2003;1:3.

3. Anderson GF, Hussey PS. Population aging: a comparison among industrialized countries. Health Aff 2000;19:191-203.

4. Hobbs FDR, Bankhead C, Mukhtar T, et al. Clinical workload in UK primary care: a retrospective analysis of 100 million consultations in England, 2007-14. Lancet 2016;387:2323-30.

5. Reeve J, Blakeman T, Freeman GK, et al. Generalist solutions to complex problems: generating practice-based evidence--the example of managing multi-morbidity. BMC Fam Pract 2013;14:112.

6. Bodenheimer T. Primary care--will it survive? N Engl J Med 2006;355:861-4.

7. Legrand SB, Heintz JB. Palliative medicine fellowship: a study of resident choices. J Pain Symptom Manage 2012;43:558-68.

8. Kim YY, Kim UN, Kim YS, et al. Factors associated with the specialty choice of Korean medical students: a cross-sectional survey. Hum Resour Health 2016;14:8.

9. McNally SA. Competition ratios for different specialties and the effect of gender and immigration status. J $R$ Soc Med 2008;101:489-92.

10. Reed VA, Jernstedt GC, Reber ES. Understanding and improving medical student specialty choice: a synthesis of the literature using decision theory as a referent. Teach Learn Med 2001;13:117-29.

11. Al-Ansari SS, Khafagy MA. Factors affecting the choice of health specialty by medical graduates. Journal of Family \& Community Medicine 2015;13:119-23.

12. Leduc N, Vanasse A, Scott I, et al. The career decision-making process of medical students and residents and the choice of specialty and practice location: how does Postgraduate Medical Education fit in? 2011.

13. Delamothe T. Modernising medical careers: final report. BMJ 2008:336:54-5.

14. Goldacre MJ, Laxton L, Harrison EM, et al. Early career choices and successful career progression in surgery in the UK: prospective cohort studies. BMC Surg 2010;10:11.

15. Weissman C, Zisk-Rony RY, Schroeder JE, et al. Medical specialty considerations by medical students early in their clinical experience. Isr J Health Policy Res 2012;1:13.
16. Jackson C, Ball J, Hirsh W, et al. Informing choices: the need for career advice in medical training. Cambridge: National institute for careers Education and Counseling, 2003.

17. Moher D, Liberati A, Tetzlaff J, et al. Preferred reporting items for systematic reviews and meta-analyses: the PRISMA statement. $J$ Clin Epidemiol 2009;62:1006-12.

18. Rostom A, Dube C, Cranney A, et al. Celiac disease. Evid Rep Technol Assess 2004;104:1-6.

19. Borenstein M, Hedges LV, Higgins JP, et al. A basic introduction to fixed-effect and random-effects models for meta-analysis. Res Synth Methods 2010;1:97-111.

20. Higgins JP, Thompson SG, Deeks JJ, et al. Measuring inconsistency in meta-analyses. BMJ 2003;327:557-60.

21. Higgins JP, Thompson SG. Quantifying heterogeneity in a metaanalysis. Stat Med 2002;21:1539-58.

22. Sterne JA, Jüni $P$, Schulz KF, et al. Statistical methods for assessing the influence of study characteristics on treatment effects in 'meta-epidemiological' research. Stat Med 2002;21:1513-24.

23. Borenstein M, Hedges LV, Higgins J, et al. Criticisms of metaanalysis. Introduction to meta-analysis 2009:377-87.

24. Egger M, Smith GD, Schneider M, et al. Bias in meta-analysis detected by a simple, graphical test. BMJ 1997;315:629-34.

25. Sterne JA, Egger M. Funnel plots for detecting bias in metaanalysis: guidelines on choice of axis. J Clin Epidemiol 2001;54:1046-55.

26. Duval S, Tweedie R. Trim and fill: a simple funnel-plot-based method of testing and adjusting for publication bias in metaanalysis. Biometrics 2000;56:455-63.

27. Bodenheimer T, Berenson RA, Rudolf P. The primary care-specialty income gap: why it matters. Ann Intern Med 2007;146:301-6.

28. Bodenheimer T, Pham HH. Primary care: current problems and proposed solutions. Health Aff 2010;29:799-805.

29. Association $\mathrm{AH}$. The hospital workforce shortage: Immediate and future. Trend Watch 2001;3:1-8.

30. Compton MT, Frank E, Elon L, et al. Changes in U.S. medical students' specialty interests over the course of medical school. $J$ Gen Intern Med 2008;23:1095-100.

31. Indyk D, Deen D, Fornari $A$, et al. The influence of longitudinal mentoring on medical student selection of primary care residencies. BMC Med Educ 2011;11:27.

32. Gill H, McLeod S, Duerksen K, et al. Factors influencing medical students' choice of family medicine: effects of rural versus urban background. Can Fam Physician 2012;58:E649-E57.

33. Richardson JD. Workforce and lifestyle issues in general surgery training and practice. Arch Surg 2002;137:515-20.

34. Newton DA, Grayson MS, Thompson LF. The variable influence of lifestyle and income on medical students' career specialty choices: data from two U.S. medical schools, 1998-2004. Acad Med 2005;80:809-14.

35. Orrico K. Ensuring an adequate neurosurgical workforce for 21 st century. Surgeons AAoN 2012

36. Wright S, Wong A, Newill C. The impact of role models on medical students. J Gen Intern Med 1997;12:53-6.

37. Glazer GM, Ruiz-Wibbelsmann JA. Decades of perceived mediocrity: prestige and radiology. Radiology 2011;260:311-6.

38. Schwartzbaum AM, McGrath JH, Rothman RA. The perception of prestige differences among medical subspecialities. Soc Sci Med 1973;7:365-71.

39. Parsa S, Aghazadeh A, Nejatisafa AA, et al. Freshmen versus interns' specialty interests. Arch Iran Med 2010;13:509-15.

40. Komorita SS. Attitude content, intensity, and the neutral point on a likert scale. J Soc Psychol 1963;61:327-34.

41. Baggaley AR, Hull AL. The effect of nonlinear transformations on a Likert scale. Eval Health Prof 1983;6:483-91.

42. Norman G. Likert scales, levels of measurement and the "laws" of statistics. Adv Health Sci Educ Theory Pract 2010;15:625-32.

43. Smith F, Lambert TW, Goldacre MJ. Factors influencing junior doctors' choices of future specialty: trends over time and demographics based on results from UK national surveys. J R Soc Med 2015;108:396-405.

44. Cochran A, Melby S, Neumayer LA. An Internet-based survey of factors influencing medical student selection of a general surgery career. Am J Surg 2005;189:742-6.

45. Hauer KE, Durning SJ, Kernan WN, et al. Factors associated with medical students' career choices regarding internal medicine. JAMA 2008;300:1154-64.

46. Johnson AL, Sharma J, Chinchilli VM, et al. Why do medical students choose orthopaedics as a career? J Bone Joint Surg Am 2012;94:e78-. 
47. Kiolbassa K, Miksch A, Hermann K, et al. Becoming a general practitioner--which factors have most impact on career choice of medical students? BMC Fam Pract 2011;12:7.

48. Klingensmith $\mathrm{ME}$, Cogbill TH, Luchette $\mathrm{F}$, et al. Factors influencing the decision of surgery residency graduates to pursue general surgery practice versus fellowship. Ann Surg 2015;262:449-55.

49. Lee JY, Kerbl DC, McDougall EM, et al. Medical students pursuing surgical fields have no greater innate motor dexterity than those pursuing nonsurgical fields. J Surg Educ 2012;69:360-3.

50. Macdonald C, Cawood T. Factors influencing career decisions in internal medicine. Intern Med J 2012;42:918-23.

51. Paiva RE, Vu NV, Verhulst SJ. The effect of clinical experiences in medical school on specialty choice decisions. J Med Educ 1982;57:666-74.

52. Ní Chróinín D, Cronin E, Cullen W, et al. Would you be a geriatrician? Student career preferences and attitudes to a career in geriatric medicine. Age Ageing 2013;42:654-7.

53. Rogers LQ, Fincher RM, Lewis LA. Factors influencing medical students to choose primary care or non-primary care specialties. Acad Med 1990;65(9 Suppl):S47-8.

54. Abendroth J, Schnell U, Lichte T, et al. Motives of former interns in general practice for speciality-choice--results of a cross-sectional study among graduates 2007 to 2012. GMS Z Med Ausbild 2014;31

55. Alawad AA, Khan WS, Abdelrazig YM, et al. Factors considered by undergraduate medical students when selecting specialty of their future careers. Pan Afr Med J 2015;20:6.

56. Azizzadeh $\mathrm{A}$, McCollum $\mathrm{CH}$, Miller $\mathrm{CC}$, et al. Factors influencing career choice among medical students interested in surgery. Curr Surg 2003;60:210-3.

57. Celenza A, Bharath J, Scop J. Improving the attractiveness of an emergency medicine career to medical students: An exploratory study. Emerg Med Australas 2012;24:625-33.

58. Dolan-Evans E, Rogers GD. Barriers for students pursuing a surgical career and where the Surgical Interest Association can intervene. ANZ J Surg 2014;84:406-11.

59. Boyd JS, Clyne B, Reinert SE, et al. Emergency medicine career choice: a profile of factors and influences from the Association of American Medical Colleges (AAMC) graduation questionnaires. Acad Emerg Med 2009;16:544-9.

60. Egerton EA. Choice of career of doctors who graduated from Queen's University, Belfast in 1977. Med Educ 1985;19:131-7.

61. Diderichsen S, Johansson EE, Verdonk P, et al. Few gender differences in specialty preferences and motivational factors: a cross-sectional Swedish study on last-year medical students. BMC Med Educ 2013:13:8.

62. Ferrari S, Reggianini C, Mattei G, et al. International study of student career choice in psychiatry (ISoSCCiP): results from Modena, Italy. Int Rev Psychiatry 2013;25:450-9.

63. Freire MC, Jordao LM, de Paula Ferreira $\mathrm{N}$, et al. Motivation towards career choice of Brazilian freshman students in a fifteenyear period. J Dent Educ 2011;75:115-21.

64. Buddeberg-Fischer B, Klaghofer R, Abel T, et al. Swiss residents' speciality choices--impact of gender, personality traits, caree motivation and life goals. BMC Health Serv Res 2006;6:137.

65. Dorsey ER, Jarjoura D, Rutecki GW. The influence of controllable lifestyle and sex on the specialty choices of graduating U.S. medical students, 1996-2003. Acad Med 2005;80:791-6.

66. Ekenze SO, Ugwumba FO, Obi UM, et al. Undergraduate surgery clerkship and the choice of surgery as a career: perspective from a developing country. World J Surg 2013;37:2094-100

67. Barikani A, Afaghi M, Barikani F, et al. Perception of the medica students on their future career in Qazvin University of Medical Sciences. Glob J Health Sci 2012;4:176-80.

68. Bittaye M, Odukogbe AT, Nyan O, et al. Medical students' choices of specialty in The Gambia: the need for career counseling. BMC Med Educ 2012;12:72.

69. Bonura EM, Lee ES, Ramsey K, et al. Factors influencing internal medicine resident choice of infectious diseases or other specialties: a National Cross-sectional Study. Clin Infect Dis 2016;63:155-63.

70. Al-Fouzan R, Al-Ajlan S, Marwan Y, et al. Factors affecting future specialty choice among medical students in Kuwait. Medical Education Online 2012;17:19587.

71. AlKot MM, Gouda MA, KhalafAllah MT, et al. Family Medicine in Egypt From Medical Students' Perspective: a Nationwide Survey. Teach Learn Med 2015;27:264-73.

72. Borges NJ, Manuel RS, Duffy RD, et al. Influences on specialty choice for students entering person-oriented and techniqueoriented specialties. Med Teach 2009;31:1086-8.

73. Budd S, Kelley R, Day R, et al. Student attitudes to psychiatry and their clinical placements. Med Teach 2011;33:e586-e592.
74. Corrigan MA, Shields CJ, Redmond HP. Factors influencing surgica career choices and advancement in Ireland and Britain. World $J$ Surg 2007;31:1921-9.

75. Davis CR, Trevatt AEJ, McGoldrick RB, et al. How to train plastic surgeons of the future. Journal of Plastic, Reconstructive \& Aesthetic Surgery 2016;69:1134-40.

76. Deutsch T, Lippmann S, Frese T, et al. Who wants to become a general practitioner? Student and curriculum factors associated with choosing a GP career--a multivariable analysis with particular consideration of practice-orientated GP courses. Scand J Prim Health Care 2015;33:47-53.

77. Gardner SP, Roberts-Thomson KF. The effect of a change in selection procedures on students' motivation to study dentistry. Aust Dent J 2014;59:2-8.

78. Dias MS, Sussman JS, Durham S, et al. Perceived benefits and barriers to a career in pediatric neurosurgery: a survey of neurosurgical residents. J Neurosurg Pediatr 2013;12:422-33.

79. Goltz CJ, Bachusz RC, Mancini E, et al. Medical student career survey--vascular surgery awareness initiative. Ann Vasc Surg 2013;27:225-31.

80. Gupta NB, Khadilkar SV, Bangar SS, et al. Neurology as career option among postgraduate medical students. Ann Indian Acad Neurol 2013:16:478-82.

81. Hanzlick R, Prahlow JA, Denton S, et al. Selecting forensic pathology as a career: a survey of the past with an eye on the future. Am J Forensic Med Pathol 2008;29:114-22.

82. Harris MC, Marx J, Gallagher PR, et al. General vs subspecialty pediatrics: factors leading to residents' career decisions over a 12year period. Arch Pediatr Adolesc Med 2005;159:212-6.

83. Hauer KE, Fagan MJ, Kernan W, et al. Internal medicine clerkship directors' perceptions about student interest in internal medicine careers. J Gen Intern Med 2008;23:1101-4.

84. Labiris G, Vamvakerou V, Tsolakaki O, et al. Perceptions of Greek medical students regarding medical profession and the specialty selection process during the economic crisis years. Health Policy 2014:117:203-9.

85. Lambert TW, Goldacre MJ, Bron AJ. Career choices for ophthalmology made by newly qualified doctors in the United Kingdom, 1974-2005. BMC Ophthalmol 2008;8:9.

86. Shah HH, Jhaveri KD, Sparks MA, et al. Career choice selection and satisfaction among US adult nephrology fellows. Clin J Am Soc Nephrol 2012;7:1513-20.

87. Lefevre JH, Roupret M, Kerneis S, et al. Career choices of medical students: a national survey of 1780 students. Med Educ 2010;44:603-12.

88. Vicente B, Rosel L. Challenges for psychiatric recruitment and training in Chile. Int Rev Psychiatry 2013;25:413-8.

89. Wiesenfeld L, Abbey S, Takahashi SG, et al. Choosing psychiatry as a career: motivators and deterrents at a critical decision-making juncture. Can J Psychiatry 2014;59:450-4.

90. Lam CY, Cheung CS, Hui AS. Factors influencing the career interest of medical graduates in obstetrics and gynaecology in Hong Kong: a cross-sectional questionnaire survey. Hong Kong Med J 2016;22:138-43.

91. Hartung PJ, Taber BJ, Richard GV. The physician values in practice scale: construction and initial validation. Journal of Vocational Behavior 2005;67:309-20.

92. Girasek E, Molnár R, Eke E, et al. The medical career choice motivations - Results from a Hungarian study. Open Med 2011;6:502-9.

93. Zuccato JA, Kulkarni AV. The impact of early medical school surgical exposure on interest in neurosurgery. Can J Neurol Sci 2016;43:410-6.

94. Wilbanks L, Spollen J, Messias E. Factors Influencing Medical School Graduates Toward a Career in Psychiatry: analysis from the 2011-2013 Association of American Medical Colleges Graduation Questionnaire. Acad Psychiatry 2016;40:255-60.

95. West CP, Drefahl MM, Popkave C, et al. Internal medicine resident self-report of factors associated with career decisions. J Gen Intern Med 2009;24:946-9.

96. Watmough S, Taylor D, Ryland I. Using questionnaires to determine whether medical graduates' career choice is determined by undergraduate or postgraduate experiences. Med Teach 2007;29:830-2.

97. Thakur A, Fedorka P, Ko C, et al. Impact of mentor guidance in surgical career selection. J Pediatr Surg 2001;36:1802-4.

98. Scott I, Gowans M, Wright B, et al. Determinants of choosing a career in surgery. Med Teach 2011;33:1011-7.

99. Schnuth RL, Vasilenko P, Mavis B, et al. What influences medical students to pursue careers in obstetrics and gynecology? Am J Obstet Gynecol 2003;189:639-43. 
100. Richards JM, Drummond R, Murray J, et al. What proportion of basic surgical trainees continue in a surgical career? A survey of the factors which are important in influencing career decisions. Surgeon 2009;7:270-5.

101. Reed CE, Vaporciyan AA, Erikson C, et al. Factors dominating choice of surgical specialty. J Am Coll Surg 2010;210:319-24.

102. Correia Lima de Souza L, Mendonça VR, Garcia GB, et al. Medical specialty choice and related factors of brazilian medical students and recent doctors. PLOS One 2015;10:15.

103. Pikoulis E, Avgerinos ED, Pedeli X, et al. Medical students' perceptions on factors influencing a surgical career: the fate of general surgery in Greece. Surgery 2010;148:510-5.

104. Ozer U, Ceri V, Carpar E, et al. Factors affecting the choice of psychiatry as a specialty and satisfaction among turkish psychiatry residents. Acad Psychiatry 2016;40:299-303.

105. Noble J, Hechter FJ, Karaiskos N, et al. Motivational factors and future life plans of orthodontic residents in the United States. Am J Orthod Dentofacial Orthop 2010;137:623-30.

106. Noble J. Factors influencing career choice in ophthalmology. Can $J$ Ophthalmol 2006;41:596-9.

107. Moore HB, Moore PK, Grant AR, et al. Future of acute care surgery: a perspective from the next generation. J Trauma Acute Care Surg 2012:72:94-9.

108. Momen AA, Shakurnia A. Factors influencing pediatric specialty choice among pediatric residents of ahvaz jundishapur university of medical sciences. International Journal of Pediatrics-Mashhad 2015;3:701-6.

109. Mehmood SI, Kumar A, Al-Binali A, et al. Specialty preferences: trends and perceptions among Saudi undergraduate medical students. Med Teach 2012;34:S51-60.

110. Loriot Y, Albiges-Sauvin L, Dionysopoulos D, et al. Why do residents choose the medical oncology specialty? Implications for future recruitment--results of the 2007 French Association of Residents in Oncology (AERIO) Survey. Ann Oncol 2010;21:161-5.

111. Lefèvre $\mathrm{JH}$, Karila L, Kerneis S, et al. Motivation of French medical students to pursue surgical careers: results of national survey of 1742 students. J Visc Surg 2010;147:e181-6.

112. Vo A, McLean L, Mclnnes MDF. Medical specialty preferences in early medical school training in Canada. Int $J$ Med Educ 2017;8:400-6.

113. Grasreiner D, Dahmen U, Settmacher U. Specialty preferences and influencing factors: a repeated cross-sectional survey of first- to sixth-year medical students in Jena, Germany. BMC Med Educ 2018:18:103.

114. Alkhaneen $\mathrm{H}$, Alhusain $\mathrm{F}$, Alshahri $\mathrm{K}$, et al. Factors influencing medical students' choice of emergency medicine as a career specialty-a descriptive study of Saudi medical students. Int J Emerg Med 2018;11:14. 